\section{- OPEN ACCESS}

\title{
Application of linear mixed-effects model with LASSO to identify metal components associated with cardiac autonomic responses among welders: a repeated measures study
}

\author{
Jinming Zhang, ${ }^{1}$ Jennifer M Cavallari, ${ }^{2}$ Shona C Fang, ${ }^{3}$ Marc G Weisskopf ${ }_{1}^{4}$ \\ Xihong Lin, ${ }^{5}$ Murray A Mittleman, ${ }^{4,6}$ David C Christiani ${ }^{1,7}$
}

${ }^{1}$ Department of Environmental Health, Harvard T H Chan School of Public Health, Boston, USA

${ }^{2}$ Department of Community Medicine and Health Care, University of Connecticut Health Center, Farmington, USA ${ }^{3}$ Department of Epidemiology, New England Research Institute, Watertown, USA

${ }^{4}$ Department of Epidemiology, Harvard T H Chan School of Public Health, Boston, USA ${ }^{5}$ Department of Biostatistics, Harvard T H Chan School of Public Health, Boston, USA ${ }^{6}$ Cardiovascular Epidemiology Research Unit, Beth Israel Deaconess Medical Center/ Harvard Medical School, Boston, USA

${ }^{7}$ Pulmonary and Critical Care Division, Massachusetts General Hospital/Harvard Medical School, Boston, USA

Correspondence to Dr David C Christiani, 665 Huntington Avenue, Building I Room 1401, Boston, Massachusetts 02115, USA dchris@hsph.harvard.edu

Received 4 September 2016 Revised 7 April 2017 Accepted 10 May 2017 Published Online First 29 June 2017
CrossMark

To cite: Zhang J, Cavallari JM, Fang SC, et al. Occup Environ Med 2017:74:810-815.

\section{ABSTRACT}

Background Environmental and occupational exposure to metals is ubiquitous worldwide, and understanding the hazardous metal components in this complex mixture is essential for environmental and occupational regulations.

Objective To identify hazardous components from metal mixtures that are associated with alterations in cardiac autonomic responses.

Methods Urinary concentrations of 16 types of metals were examined and 'acceleration capacity' (AC) and 'deceleration capacity' (DC), indicators of cardiac autonomic effects, were quantified from ECG recordings among 54 welders. We fitted linear mixed-effects models with least absolute shrinkage and selection operator (LASSO) to identify metal components that are associated with AC and DC. The Bayesian Information Criterion was used as the criterion for model selection procedures.

Results Mercury and chromium were selected for DC analysis, whereas mercury, chromium and manganese were selected for AC analysis through the LASSO approach. When we fitted the linear mixed-effects models with 'selected' metal components only, the effect of mercury remained significant. Every $1 \mu \mathrm{g} / \mathrm{L}$ increase in urinary mercury was associated with $-0.58 \mathrm{~ms}(-1.03$, $-0.13)$ changes in $D C$ and $0.67 \mathrm{~ms}(0.25,1.10)$ changes in $\mathrm{AC}$.

Conclusion Our study suggests that exposure to several metals is associated with impaired cardiac autonomic functions. Our findings should be replicated in future studies with larger sample sizes.

\section{INTRODUCTION}

In recent years, toxic metal pollution has become one of the major environmental problems across the globe due to increase in industrialisation and anthropogenic activities. There has been increasing concern over the impact of metals exposure on cardiovascular diseases (CVD). ${ }^{1-3}$ Studies have shown that alterations in cardiac autonomic responses might be one of the potential mechanisms of cardiovascular effects of metals exposure. ${ }^{45}$ The imbalance between sympathetic and parasympathetic activities is associated with increased cardiovascular morbidity and mortality. ${ }^{67}$

\section{What this paper adds}

Welder are exposed to a mixture of variety types of metals existed in the welding fume during the welding process.

- Previous studies have indicated that welders have higher risks of cardiovascular autonomic dysfunction due to occupational welding fumes exposure compared with the general population.

- This paper suggests that occupational mercury, chromium and manganese exposures may be associated with higher risk of cardiac autonomic dysfunction among welders.

- Interventions should aim at reducing metal-rich welding fumes exposure to mitigate cardiac autonomic alterations in the occupational setting.

Conventional heart rate variability (HRV) parameters, including SD of NN intervals (SDNN), the root mean square of heartbeat interval differences (RMSSDs), high frequency (HF) and low frequency (LF), have been widely used as indicators of cardiac autonomic responses. However, recent studies suggested that these HRV parameters might not be accurate as they failed to account for heart rate, a potential confounder. ${ }^{8}$ One possible solution might be the phase-rectified signal averaging (PRSA) approach introduced by Bauer et al. ${ }^{9}$ Using this method, the deceleration and acceleration were separately characterised through two novel markers: acceleration capacity (AC) and deceleration capacity (DC). DC provides a measure of parasympathetic modulation of heart rate. Decreased DC, an indicator for the impaired cardiac autonomic functions, has been a strong predictor of cardiovascular mortality among patients after myocardial infarction. ${ }^{910}$

Welders are exposed to various types of metals from welding fumes. Welding materials often consist of mixtures of metals, such as iron, manganese, chromium and nickel. ${ }^{11}$ Metal-rich welding fumes are small particles consisting of mostly vapourised metals that are suspended in air. ${ }^{12}$ Previous studies have reported a higher risk of cardiac autonomic dysfunction associated with fine particulate 
matters (PM2.5) exposure from welding fumes. ${ }^{13}{ }^{14}$ However, few studies have examined the health effects of specific metal components. Understanding the hazardous metal species responsible for the adverse cardiac effects will have important implications for regulations in occupational settings. Therefore, in the current study, we examined the association between 16 metal species and AC and DC values. To address the challenge of disentangling effects of correlated metals in a mixture in the welding fume, we conducted model selection procedures via least absolute shrinkage and selection operator (LASSO) to identify metal components that are significantly associated with alterations in cardiac autonomic functions.

\section{METHODS}

\section{Study population}

The study population included a total of 54 welders from a local boilermaker union in Quincy, Massachusetts. Participants were recruited and monitored over four sampling occasions in the summer and winter months - June 2010, January 2011, June 2011 and June 2012, periods of boilermaker 'off-season' at the union welding school - and were invited to participate in multiple sampling occasions. All participants were male workers who (1) were 18 years of age or older; (2) were union apprentice or journeyman; (3) were free of CVD at first entry; and (4) provided urine and ECG samples at least once over the four sampling occasions.

We monitored each participant for approximately 6 hours during a 'work-shift' at each sampling occasion. The major tasks were welding, cutting and grinding activities at a union welding school. Participants performed electric arc welding, using base metals of mild steel and stainless steel. Each participant provided a urine sample and resting ECG recordings at both prior (baseline) and post work. We collected questionnaires on demographics including age, height, weight, smoking status, medical history and medication use from participants at baseline. We obtained informed written consent from each participant prior to participation. The Harvard TH Chan School of Public Health Institutional Review Board approved our study protocol.

\section{ECG recordings and sample analysis}

During each sampling occasion, participants were fitted with a 7-lead ambulatory ECG Holter monitor. We collected $12 \mathrm{~min}$ resting ECG recordings from each participant at both prior and post work-shift. During the $12 \mathrm{~min}$ resting period, participants were asked to remain seated and quiet; walking, talking or eating was not allowed, as AC and DC are sensitive to these activities. The ECG samples were then sent to the Cardiovascular Epidemiology Research Unit of Beth Israel Deaconess Medical Center (Boston, Massachusetts, USA), where trained technicians blinded to exposure status processed and analysed these samples. The methods of processing ECG samples for AC and DC analysis have been discussed in a prior study. ${ }^{15} \mathrm{AC}$ and DC quantities were computed and summarised every $5 \mathrm{~min}$ through the PRSA method, as described by Bauer et al. In brief, to compute DC values, RR intervals longer than the immediate preceding interval were defined as anchors; to compute AC values, RR intervals shorter than the immediate preceding interval were defined as anchors. Segments of interval data that had the same size around these anchors were identified. On alignment of all segments, $\mathrm{RR}$ intervals at all defined anchors (X0), immediately preceding (X1) and following the anchors (X-1) were averaged separately. The quantities of AC or DC were obtained by computing the difference between the sum of $\mathrm{X} 0$ and $\mathrm{X} 1$ and the sum of $(\mathrm{X}-1)$ and $(\mathrm{X}-2) .{ }^{9}$ To account for acclimation, the first $2 \mathrm{~min}$ of the 12 min resting ECG recordings was discarded and the remaining $10 \mathrm{~min}$ recordings were summarised as two non-overlapping 5 min AC or DC values (3rd-7th and 8th-12th minute intervals). We collected a total of 280 five-minute AC or DC values.

\section{Measurement of urinary metals and creatinine}

During each sampling occasion, participants provided urine samples at both baseline and postexposure. A total of 171 samples were collected during the four sampling occasions. Each urine sample was collected with a $120 \mathrm{~mL}$ sterile urine collection cup and temporarily kept on ice. An approximately $12 \mathrm{~mL}$ aliquot of urine was then transferred to $15 \mathrm{~mL}$ Falcon tubes for storage in a freezer at $-20^{\circ} \mathrm{C}$. The urine samples were sent to Brooks Rand Labs, where the urinary concentrations of 16 types of metals were determined. The inductively coupled plasma mass spectrometry (ICP-MS) was used to analyse aluminium $(\mathrm{Al})$, copper $(\mathrm{Cu})$, manganese $(\mathrm{Mn})$, lead $(\mathrm{Pb})$, zinc $(\mathrm{Zn})$, cobalt (Co), vanadium $(\mathrm{V})$, magnesium $(\mathrm{Mg})$, molybdenum $(\mathrm{Mo})$ and cadmium (Cd) concentrations, while the ICP-MS with dynamic reaction cell technology was used for iron (Fe), chromium (Cr), arsenic (As), selenium (Se) and nickel (Ni) analysis. In addition, the urinary mercury $(\mathrm{Hg})$ concentration was determined using cold-vapour atomic fluorescence spectrometry. Measurements of both baseline and postexposure urinary metal species were obtained and used. For quality control purpose, duplicate, matrix spike and matrix spike duplicate analyses, as well as NIST SRM 1643e (certified reference material with trace elements in natural water), were used. The method detection limit for urinary metals measurements ranged from 0.01 to $3.30 \mu \mathrm{g} / \mathrm{L}$. In addition, urinary creatinine levels were also determined.

\section{Statistical analysis}

In this study, we examined the urinary concentrations of 16 types of metals: $\mathrm{Cr}, \mathrm{Fe}, \mathrm{Cu}, \mathrm{Mn}, \mathrm{Ni}, \mathrm{Pb}, \mathrm{V}, \mathrm{Zn}, \mathrm{Cd}, \mathrm{As}, \mathrm{Mg}, \mathrm{Hg}$, Co, $\mathrm{Mo}$, Se and $\mathrm{Al}$, including metals that are commonly found in the welding fumes, as well as trace metals that have been associated with CVDs from previous research. A group of covariates were controlled for, including baseline age (a continuous variable in years), body mass index (BMI; calculated as weight in kilograms divided by height squared in metres), current smoking status (categorised into two groups: non-smoker, and former smoker or current smoker), time (baseline or postwork) and season (summer or winter when each sampling occasion occurred). These variables have been reported as predictors of cardiac autonomic responses. A variable 'time in day' was also adjusted for as AC and DC might exhibit a circadian pattern throughout the day. ${ }^{16}$ In addition, urinary creatinine level was included in the model as a covariate as studies suggested the potential bias might be introduced when using the creatinine-standardised metal concentration (the ratio of metal concentrations over creatinine levels). ${ }^{17}$

Tibshirani ${ }^{18}$ introduced the idea of 'least absolute shrinkage and selection operator' (LASSO), which applies an $\mathrm{L}_{1}$ penalty to 'minimize the residual sum of squares subject to the sum of the absolute value of the coefficients being less than a constant'. ${ }^{18}$ LASSO can be used when the study sample size is very small or when the number of parameters is larger than the number of samples. We conducted linear mixed-effects models with LASSO to further account for correlations of repeated measurements from the same subject. The linear mixed-effects models with random subject-specific intercepts assessing metals exposure on $\mathrm{AC}$ or DC changes $\left(\mathrm{Y}_{\mathrm{ij}}\right)$ were fitted as follows: 
Table 1 Demographics of study populations at first entry $(n=54)$

\begin{tabular}{ll}
\hline Characteristics & $\mathbf{N}(\%)$ or mean \pm SD \\
\hline Male & $\mathbf{5 4}(\mathbf{1 0 0})$ \\
\hline Age (years) & $41.6(12.4)$ \\
\hline Range & $\mathbf{2 1 . 7 - 7 1 . 2}$ \\
\hline Body mass index $\left(\mathrm{kg} / \mathrm{m}^{2}\right)$ & $\mathbf{2 8 \pm 4}$ \\
\hline Race & \\
\hline Caucasian & $50(92.6)$ \\
African-American & $2(3.7)$ \\
\hline Hispanic & $2(3.7)$ \\
\hline Asian & $0(0)$ \\
Current smoker & $22(40.7)$ \\
Acceleration capacity (ms) & $-6.29(3.62)$ \\
\hline Deceleration capacity (ms) & $7.62(3.23)$ \\
\hline
\end{tabular}

$\mathrm{Y}_{\mathrm{ij}}=\mathrm{X}_{\mathrm{i}} \beta+\gamma_{1}$ Age $_{\mathrm{ij}}+\gamma_{2} \mathrm{BMI}_{\mathrm{ij}}+\gamma_{3}$ Time in day $_{\mathrm{ij}}+\gamma_{4}$ smoking status $_{\mathrm{ij}}+\gamma_{5}$ Time $_{\mathrm{ij}}+\gamma_{6}$ Season $_{\mathrm{ij}}+\mathrm{b}_{\mathrm{i}}+\varepsilon_{\mathrm{ij}}$

where $Y_{i j}$ indicates AC or DC measurements of subject $i$ at jth time, $\varepsilon_{i j} \sim N\left(0, \sigma^{2}\right.$ and $b_{i} \sim N\left(0, \sigma_{b}{ }^{2}\right), \beta=\left(\beta_{i 1}, \ldots, \beta_{i j}\right)^{T}$ indicates a vector of regression coefficients of metals species vector $\mathrm{X}_{\mathrm{i}}=\left(\mathrm{X}_{\mathrm{i} 1}, \ldots, \mathrm{X}_{\mathrm{ij}}\right)$ that is 'selected' via LASSO with $\mathrm{L}_{1}$ penalty. To identify and select metal component species associated with AC and DC, a penalty term was applied to all urinary metal species only, but not the other covariates (ie, they were 'fixed' covariates in the model).

When $\mathrm{L}_{1}$ penalty is applied, a non-negative tuning parameter $\lambda$ is used to determine the amount of shrinkage or penalisation. For example, when $\lambda$ is small, the model coefficients of all metal species are weakly penalised and are similar to those estimated from a regular linear mixed-effects model; when $\lambda$ is large enough, the model coefficients of all metal species are strongly penalised, the shrinkage tends towards the null (0), and the final model will only include the 'fixed' covariates; when $\lambda$ takes a value in between the extreme values, the model coefficients of some metal species are 0 , while those of the others are non-zero in the penalised model. In this study, we ran all models across the range of $\lambda \mathrm{s}$. The Bayesian Information Criterion (BIC) ${ }^{19}$ was used as the criterion for model selection, and the $\lambda$ in a model with the smallest BIC was identified and selected. Since LASSO did not provide SEs for the selected metal species, we then fitted a final linear mixed-effects model including selected metal species and aforementioned 'fixed' covariates. In addition, we also conducted linear mixed-effects models to estimate pairwise correlations between metal species. All statistical analyses were performed with SAS V.9.3 and R V.3.2.2 (R Core Team 2015).

\section{RESULTS}

Demographic descriptions of the study population are summarised in table 1 . Among 54 male welders, there were 22 (40.7\%) current smokers and 32 (59.3\%) former smokers or non-smokers. The average age was 41.6 (ranged from 21.7 to 71.2 years). The average BMI was $28 \mathrm{~kg} / \mathrm{m}^{2}$. The median urinary metals concentrations ranged from $0.18 \mu \mathrm{g} / \mathrm{L}$ to $77.55 \mathrm{mg} / \mathrm{L}$ at baseline and $0.19 \mu \mathrm{g} / \mathrm{L}$ to $82.30 \mathrm{mg} / \mathrm{L}$ at post work. The distribution of urinary metals concentrations was skewed (table 2).

The relationship between $\lambda$ and model BIC, the criterion for model selection procedures, is shown in figure 1 . For DC analysis, there was maximum shrinkage when $\lambda=20$; the model with the smallest BIC $(\lambda=9)$ included $\mathrm{Hg}$ and $\mathrm{Cr}$ only, and the regression coefficients of all the other metal components were 0 . For AC analysis, the model with the smallest $\operatorname{BIC}(\lambda=6)$ included $\mathrm{Mn}$, in addition to $\mathrm{Hg}$ and $\mathrm{Cr}$, and there was maximum shrinkage when $\lambda=21$.

When we fitted the linear mixed-effects models with 'fixed' covariates and 'selected' metal components only, there were negative associations of urinary $\mathrm{Hg}$ and $\mathrm{Cr}$ levels with $\mathrm{DC}$, whereas there were positive associations of urinary $\mathrm{Hg}, \mathrm{Cr}$ and $\mathrm{Mn}$ levels with AC. However, only the effects of $\mathrm{Hg}$ exposure exhibited statistical significance, and the effects of $\mathrm{Cr}$ and $\mathrm{Mn}$ exposure were marginally significant. A $1 \mu \mathrm{g} / \mathrm{L}$ increase in urinary $\mathrm{Hg}$ was associated with $-0.58 \mathrm{~ms}(-1.03,-0.13)$ change in $\mathrm{DC}$ and $0.67 \mathrm{~ms}(0.25,1.10)$ change in AC (table 3$)$. The correlation coefficients of urinary $\mathrm{Hg}$ and $\mathrm{Cr}, \mathrm{Cr}$ and $\mathrm{Mn}$, as well as $\mathrm{Hg}$ and $\mathrm{Mn}$ that were estimated through linear mixed-effects models were $0.46,0.37$ and 0.29 , respectively.

\section{DISCUSSION}

Overall our findings suggested that exposure to metals was associated with adverse cardiac autonomic responses. A total of 16 urinary metal species were examined, and their half-lives in

Table 2 Summaries of urinary metals concentrations at preshift and postshift

\begin{tabular}{|c|c|c|c|c|c|c|c|c|c|c|c|c|}
\hline \multirow[b]{2}{*}{ Metals } & \multicolumn{6}{|c|}{ Preshift } & \multicolumn{6}{|c|}{ Postshift } \\
\hline & Mean & P5 & P25 & P50 & P75 & P95 & Mean & P5 & P25 & P50 & P75 & P95 \\
\hline Chromium ( $\mu \mathrm{g} / \mathrm{L})$ & 0.30 & 0.10 & 0.12 & 0.22 & 0.41 & 0.67 & 0.45 & 0.10 & 0.16 & 0.27 & 0.46 & 1.19 \\
\hline Iron (mg/L) & 0.23 & 0.03 & 0.09 & 0.18 & 0.36 & 0.55 & 0.22 & 0.03 & 0.10 & 0.20 & 0.30 & 0.51 \\
\hline Copper $(\mu \mathrm{g} / \mathrm{L})$ & 10.51 & 2.63 & 5.55 & 9.06 & 14.20 & 22.00 & 11.36 & 2.73 & 6.17 & 9.53 & 14.10 & 25.40 \\
\hline Manganese ( $\mu \mathrm{g} / \mathrm{L})$ & 2.23 & 0.40 & 1.18 & 1.99 & 2.87 & 4.72 & 2.52 & 0.50 & 1.51 & 2.11 & 3.49 & 5.16 \\
\hline Nickel $(\mu \mathrm{g} / \mathrm{L})$ & 1.63 & 0.50 & 0.66 & 1.23 & 2.26 & 3.86 & 1.79 & 0.50 & 0.95 & 1.52 & 2.39 & 4.03 \\
\hline Lead ( $\mu \mathrm{g} / \mathrm{L})$ & 0.51 & 0.08 & 0.23 & 0.36 & 0.77 & 1.27 & 0.70 & 0.10 & 0.31 & 0.49 & 0.89 & 2.02 \\
\hline Vanadium ( $\mu \mathrm{g} / \mathrm{L})$ & 0.26 & 0.10 & 0.10 & 0.18 & 0.40 & 0.69 & 0.24 & 0.10 & 0.10 & 0.22 & 0.36 & 0.53 \\
\hline Zinc (mg/L) & 0.48 & 0.07 & 0.19 & 0.39 & 0.65 & 1.10 & 0.46 & 0.09 & 0.23 & 0.39 & 0.61 & 1.05 \\
\hline Cadmium ( $\mu \mathrm{g} / \mathrm{L})$ & 0.34 & 0.07 & 0.09 & 0.20 & 0.42 & 0.97 & 0.32 & 0.07 & 0.12 & 0.19 & 0.32 & 0.79 \\
\hline Arsenic $(\mu \mathrm{g} / \mathrm{L})$ & 32.22 & 2.50 & 4.53 & 9.58 & 19.40 & 128.56 & 24.06 & 3.19 & 6.68 & 12.50 & 27.70 & 89.10 \\
\hline Magnesium (mg/L) & 87.29 & 19.00 & 38.40 & 77.55 & 114.00 & 213.00 & 89.63 & 15.70 & 52.90 & 82.30 & 114.00 & 170.00 \\
\hline Mercury $(\mu \mathrm{g} / \mathrm{L})$ & 0.71 & 0.10 & 0.21 & 0.52 & 1.01 & 2.21 & 0.69 & 0.07 & 0.21 & 0.41 & 0.74 & 2.46 \\
\hline Cobalt $(\mu \mathrm{g} / \mathrm{L})$ & 0.49 & 0.35 & 0.40 & 0.40 & 0.52 & 0.78 & 0.52 & 0.32 & 0.40 & 0.44 & 0.57 & 0.95 \\
\hline Molybdenum ( $\mu \mathrm{g} / \mathrm{L})$ & 50.28 & 6.50 & 23.80 & 38.70 & 60.90 & 147.00 & 66.15 & 12.60 & 37.60 & 52.70 & 80.50 & 149.00 \\
\hline Selenium ( $\mu g / L)$ & 63.74 & 12.20 & 35.90 & 56.30 & 83.50 & 159.00 & 75.49 & 21.40 & 44.70 & 66.71 & 96.90 & 152.00 \\
\hline Aluminium $(\mu \mathrm{g} / \mathrm{L})$ & 6.25 & 3.30 & 3.30 & 3.30 & 6.31 & 19.80 & 6.12 & 3.30 & 3.30 & 3.48 & 6.66 & 18.40 \\
\hline
\end{tabular}




\section{DC- Lambda vs BIC plot}

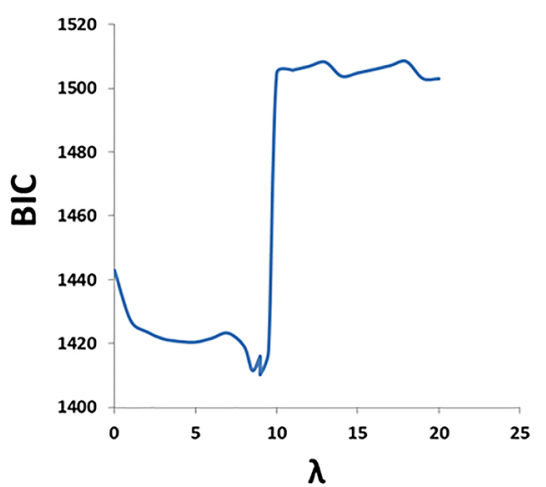

AC- Lambda vs BIC plot

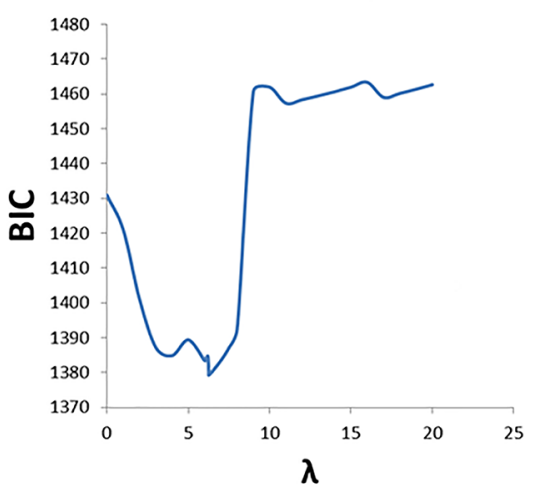

Figure 1 The relationship between $\lambda$, the penalisation factor, and model BIC, the criterion for model selection. AC, acceleration capacity; BIC, Bayesian Information Criterion; DC, deceleration capacity.

urine vary from a few hours to a few months. We used linear mixed-effects models with LASSO shrinkage method to identify metal components that might be associated with AC or DC. We observed that urinary $\mathrm{Hg}$ and $\mathrm{Cr}$ concentrations were negatively associated with DC, whereas urinary $\mathrm{Hg}, \mathrm{Cr}$ and $\mathrm{Mn}$ concentrations were positively associated with AC. The significant effects of $\mathrm{Hg}$ exposure on $\mathrm{AC}$ and $\mathrm{DC}$ persisted in the copollutant models, while the effects of $\mathrm{Cr}$ and $\mathrm{Mn}$ yielded marginal significance. Our findings suggested that metals exposure might induce imbalance between sympathetic and parasympathetic activities.

Mercury is classified in three major groups: elemental mercury, inorganic mercury compounds and organic mercury. To date, several biomarkers have been used to assess $\mathrm{Hg}$ exposure, such as hair, blood and urine samples. ${ }^{20}{ }^{21} \mathrm{Hg}$ levels in blood and hair are indicators of organic $\mathrm{Hg}$ exposures, whereas urinary $\mathrm{Hg}$ concentration mainly reflects exposure to elemental or inorganic forms of $\mathrm{Hg}$. In the current study, we used urinary $\mathrm{Hg}$ concentrations to estimate medium-term $\mathrm{Hg}$ exposure, as it has a half-life of approximately 1-3 months in urine. The baseline median value $(0.52 \mu \mathrm{g} / \mathrm{L})$ was similar to the US population medians from National Health ${ }^{22}$ and Nutrition Examination Survey $(0.48 \mu \mathrm{g} / \mathrm{L})^{22}$ and $17.5 \%$ lower than the values $(0.63 \mu \mathrm{g} / \mathrm{L})$ from a study in a dental professionals cohort. ${ }^{23}$

While $\mathrm{Hg}$ has long been considered as an environmental and occupational neurotoxicant, there has been increasing concern about the cardiotoxic effects of $\mathrm{Hg}$ exposure. Several studies have documented the role of organic $\mathrm{Hg}$ exposure in triggering cardiac autonomic responses. For example, Lim et al ${ }^{24}$ examined hair $\mathrm{Hg}$ levels and HRV in a cross-sectional study among 1589 residents living near industrial complexes in South Korea, and it was found that a 1 parts per million (ppm) increase in hair $\mathrm{Hg}$ concentration was associated with an $8.4 \%$ decline in HF parameter. In a clinical trial where 27 participants in the intervention group were instructed to consume bigeye tuna and swordfish once a week for 14 weeks, while 27 participants in the control group continued usual diets, participants in the intervention group had significantly higher ratio of LF to $\mathrm{HF}$ at the end of the study over the control group. ${ }^{25}$ On the other hand, epidemiological research investigating the cardiovascular effects of elemental or inorganic $\mathrm{Hg}$ exposure has mainly focused on blood pressure. ${ }^{2627}$ To our knowledge, this is the first study reporting the association of element or inorganic $\mathrm{Hg}$ exposure and cardiac autonomic responses in humans.

Furthermore, it is notable that these welders might be exposed to elemental or inorganic mercury from ambient environment rather than occupational settings, as $\mathrm{Hg}$ is not a common welding fume component. Studies have reported ubiquitous exposure to inorganic forms of $\mathrm{Hg}$ among the population in USA and Canada. ${ }^{22}{ }^{28}$ Elemental mercury is often used in products like thermometers and dental amalgam. ${ }^{29} 30$ In the general population, elemental mercury from dental amalgam is one of the major sources of $\mathrm{Hg}$ exposure. Inorganic mercury compounds have been widely used in batteries or organic chemicals. In addition, urinary mercury levels could also change due to high fish consumption. $^{31}$

On the other hand, $\mathrm{Cr}$ and $\mathrm{Mn}$ are both common components that exist in welding fumes. These vapourised metal components become small particles that could suspend and react with oxygen in the air throughout the welding process. Cr can be found in two forms: trivalent chromium (Cr(III)) or hexavalent chromium $(\mathrm{Cr}(\mathrm{VI}))$. $\mathrm{Cr}(\mathrm{VI})$ is a well-established environmental pollutant and is much more toxic than $\mathrm{Cr}(\mathrm{III}) .{ }^{32}$ Inhalation, digestion and dermal absorption were the main pathway of occupational $\mathrm{Cr}$ exposure. In the current study, we measured short-term $\mathrm{Cr}(\mathrm{VI})$ exposure through urinary $\mathrm{Cr}(\mathrm{VI})$ concentrations, which reflect exposure over approximately 1-2 days. ${ }^{33}$ We observed a significant association between occupational Cr exposures and impaired cardiac autonomic effects. Similarly, Cavallari et $a^{34}$ found that airborne $\mathrm{Cr}(\mathrm{VI})$ exposure was associated with reduced nocturnal RMSSD among this welder population. However, evidence from epidemiological studies was

Table 3 Effects of copollutants exposure on AC or DC changes

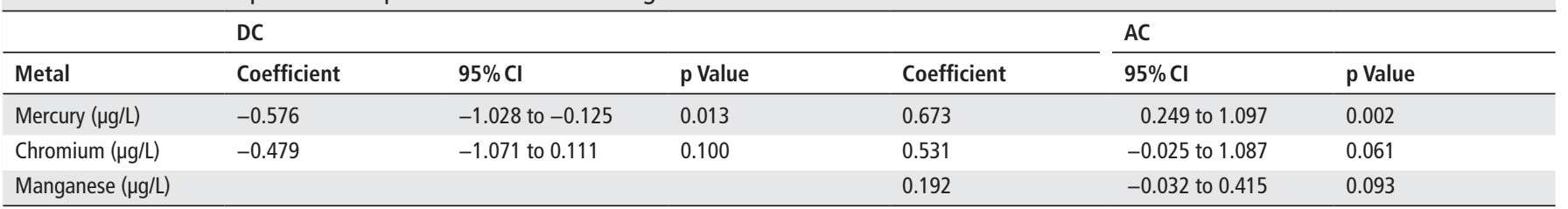

$\mathrm{AC}$, acceleration capacity; $\mathrm{DC}$, deceleration capacity. 
very limited and the cardiotoxicity of $\mathrm{Cr}(\mathrm{VI})$ exposure warrants further research.

In addition, urinary $\mathrm{Mn}$ concentrations were used to estimate recent airborne manganese from welding fumes among these welders. ${ }^{35}$ Previous studies have documented the association of $\mathrm{Mn}$ exposure and annual cardiovascular mortality, as well as Mn being a modifier of the association between PM2.5 exposure and hospital admissions for CVD. ${ }^{36}$ Consistent with research on airborne $\mathrm{Mn}$ among manganese alloy workers ${ }^{37}$ and boilermaker construction workers, ${ }^{34}$ our studies suggested that urinary Mn levels were associated with impaired cardiac autonomic functions.

Although the underlying mechanisms of metals exposure on cardiovascular effects are still under investigation, studies suggested that oxidative stress, inflammatory responses and enzymatic inhibition ${ }^{38-40}$ might play a role. Transition metals, such as $\mathrm{Hg}, \mathrm{Cr}$ and $\mathrm{Mn}$, may undergo redox cycling reactions and induce oxidative stress through enhanced generation of reactive oxygen species. ${ }^{38}$ Low concentrations of $\mathrm{Hg}$ exposure may induce decreased nitrogen monoxide (NO) bioavailability due to oxidative stress and further promote endothelial dysfunction in both resistance and conductance arteries in male Wistar rats. ${ }^{41}$ Furthermore, decreased HRV parameters (SDNN, SD1 (standard deviation of the instantaneous beat-to-beat variability) and SD2 (long term variability of continuous RR intervals)) following peripheral injection of interleukin 6, a proinflammatory cytokine, were documented in another toxicological study. ${ }^{40}$ Taken together, future studies examining oxidative stress and inflammation as the mediators linking metals exposure and cardiovascular effects may be essential for illustrating the underlying causal pathway.

To our knowledge, this is the first repeated measurements study investigating metal components exposure and cardiac autonomic effects. We used linear mixed-effects models with LASSO for model selection procedures, and this approach has several advantages over conventional methods. Typically, researchers examined the effects of metal components by fitting a model including all components simultaneously. However, collinearity issues due to high correlations among metal components may induce inflated variances of the estimated regression coefficients and sap the statistical power. ${ }^{42}$ Another commonly used approach, stepwise regression, may have similar problems in the presence of collinearity, as well as yield biased coefficients that need shrinkage. ${ }^{18}$

When we fitted 'selected' metals only in the copollutant model, the effects of $\mathrm{Cr}$ and $\mathrm{Mn}$ were only marginally significant. This may be due to the relatively small sample size and the modest correlations among these metal components. It is also notable that metals may often induce antagonistic, additive or synergistic responses in the presence of other metal components. For example, Papp et $a l^{43}$ observed synergistic neurotoxicity of combined exposure of $\mathrm{Hg}, \mathrm{Mn}$ and $\mathrm{Pb}$ among male Wistar rats. ${ }^{43}$ While the exact relationships between $\mathrm{Hg}, \mathrm{Cr}$ and $\mathrm{Mn}$ in triggering cardiac autonomic effects were unclear, it is possible that model misspecification may also occur in this study as we assumed independent relationships among these components in the copollutant model. Future studies may examine the overall effect of the mixture by accounting for the possible interplay among metal species.

Several other limitations to our study should be considered. First, we acknowledge that fitting a linear mixed-effects model including selected metal species by LASSO may not be ideal for estimating the SEs or $\mathrm{p}$ values and may yield narrow CIs, since they fail to include a penalty term used in LASSO. Second, urinary concentrations of some metals ${ }^{44}$ may not be ideal for assessing metals exposures, and non-differential exposure misclassification may be possible, and measurement errors may also occur due to individual variability in the excretion of metal and creatinine in urine. Third, there may be healthy worker effect if these welders tend to be healthier compared with non-working population. Finally, our study had a relatively small sample size and the results from our study need to be replicated in additional studies of metal-exposed workers.

Acknowledgements We thank the participants and leadership from Local 29 of International Brotherhood of Boilermaker (Quincy, MA)

Contributors IZ contributed to all aspects of data acquisition, data analysis and interpretation, and preparation of the manuscript. DCC contributed to the study conception and design, data collection, analysis and interpretation. JMC and SCF contributed to the data collection and interpretation of the results. MAM, MGW and $\mathrm{XL}$ contributed to the data analysis and interpretation of the results. All authors reviewed and approved the manuscript.

Competing interests None declared.

Patient consent Obtained.

Ethics approval The Harvard T H Chan School of Public Health Institutional Review Board.

Provenance and peer review Not commissioned; externally peer reviewed.

Open Access This is an Open Access article distributed in accordance with the Creative Commons Attribution Non Commercial (CC BY-NC 4.0) license, which permits others to distribute, remix, adapt, build upon this work non-commercially, and license their derivative works on different terms, provided the original work is properly cited and the use is non-commercial. See: http://creativecommons.org/ licenses/by-nc/4.0/

(c) Article author(s) (or their employer(s) unless otherwise stated in the text of the article) 2017. All rights reserved. No commercial use is permitted unless otherwise expressly granted.

\section{REFERENCES}

1 Solenkova NV, Newman JD, Berger JS, Thurston G, et al. Metal pollutants and cardiovascular disease: mechanisms and consequences of exposure. Am Heart $J$ 2014; 168:812-22.

2 Navas-Acien A, Selvin E, Sharrett AR, et al. Lead, cadmium, smoking, and increased risk of peripheral arterial disease. Circulation 2004;109:3196-201.

3 Alissa EM, Ferns GA. Heavy metal poisoning and cardiovascular disease. J Toxicol 2011:2011:1-21.

4 Feng W, He X, Chen M, et al. Urinary metals and heart rate variability: a crosssectional study of urban adults in Wuhan, China. Environ Health Perspect 2015;123:217-22.

5 Magari SR, Schwartz J, Williams PL, et al. The association of particulate air metal concentrations with heart rate variability. Environ Health Perspect 2002:110:875-80.

6 Nolan J, Batin PD, Andrews R, et al. Prospective study of heart rate variability and mortality in chronic heart failure: results of the United Kingdom heart failure evaluation and assessment of risk trial (UK-heart). Circulation 1998;98:1510-6.

7 Chandola T, Britton A, Brunner E, et al. Work stress and coronary heart disease: what are the mechanisms? Eur Heart J 2008:29:640-8.

8 Monfredi 0 , Lyashkov $A E$, Johnsen $A B$, et al. Biophysical characterization of the underappreciated and important relationship between heart rate variability and heart rate. Hypertension 2014;64:1334-43

9 Bauer A, Kantelhardt JW, Barthel P, et al. Deceleration capacity of heart rate as a predictor of mortality after myocardial infarction: cohort study. Lancet 2006;367:1674-81

10 Schneider A, Hampel R, Ibald-Mulli A, et al. Changes in deceleration capacity of heart rate and heart rate variability induced by ambient air pollution in individuals with coronary artery disease. Part Fibre Toxicol 2010;7:29.

11 Antonini JM. Health effects of welding. Crit Rev Toxicol 2003;33:61-103.

12 Wong JY, Fang SC, Grashow R, et al. The relationship between occupational metal exposure and arterial compliance. J Occup Environ Med 2015;57:355-60.

13 Fan T, Fang SC, Cavallari JM, et al. Heart rate variability and DNA methylation levels are altered after short-term metal fume exposure among occupational welders: a repeated-measures panel study. BMC Public Health 2014;14:1279.

14 Scharrer $E$, Hessel $H$, Kronseder A, et al. Heart rate variability, hemostatic and acute inflammatory blood parameters in healthy adults after short-term exposure to welding fume. Int Arch Occup Environ Health 2007;80:265-72.

15 Umukoro PE, Cavallari JM, Fang SC, et al. Short-term metal particulate exposures decrease cardiac acceleration and deceleration capacities in welders: a repeatedmeasures panel study. Occup Environ Med 2016;73:91-6. 
16 Cavallari JM, Fang SC, Mittleman MA, et al. Circadian variation of heart rate variability among welders. Occup Environ Med 2010;67:717-9.

17 Barr DB, Wilder LC, Caudill SP, et al. Urinary creatinine concentrations in the U.S. population: implications for urinary biologic monitoring measurements. Environ Health Perspect 2005;113:192-200.

18 Tibshirani R. Regression shrinkage and selection via the lasso. J R Stat Soc Series $B$ Stat Methodol 1996;58:267-88.

19 Schwarz G. Estimating the dimension of a Model. The Annals of Statistics 1978;6:461-4.

20 McDowell MA, Dillon CF, Osterloh J, et al. Hair mercury levels in U.S. children and women of childbearing age: reference range data from NHANES 1999-2000. Environ Health Perspect 2004;112:1165-71.

21 Somers EC, Ganser MA, Warren JS, et al. Mercury exposure and antinuclear antibodies among females of Reproductive Age in the United States: nhanes. Environ Health Perspect 2015:123:792-8.

22 Crinnion WJ. The CDC fourth national report on human exposure to environmental chemicals: what it tells Us about our toxic burden and how it assist environmental medicine physicians. Altern Med Rev 2010;15:101-9.

23 Goodrich JM, Wang Y, Gillespie B, et al. Methylmercury and elemental mercury differentially associate with blood pressure among dental professionals. Int J Hyg Environ Health 2013;216:195-201.

24 Lim S, Chung HU, Paek D. Low dose mercury and heart rate variability among community residents nearby to an industrial complex in Korea. Neurotoxicology 2010;31:10-16

25 Yaginuma-Sakurai K, Murata K, Shimada M, et al. Intervention study on cardiac autonomic nervous effects of methylmercury from seafood. Neurotoxicol Teratol 2010;32:240-5.

26 Valera B, Dewailly E, Poirier P. Environmental mercury exposure and blood pressure among Nunavik Inuit adults. Hypertension 2009;54:981-6.

27 Kobal AB, Horvat M, Prezelj $M$, et al. The impact of long-term past exposure to elemental mercury on antioxidative capacity and lipid peroxidation in mercury miners. J Trace Elem Med Biol 2004;17:261-74.

28 Nicolae A, Ames H, Quiñonez C. Dental amalgam and urinary mercury concentrations: a descriptive study. BMC Oral Health 2013;13:44.

29 Kingman A, Albertini T, Brown LJ. Mercury concentrations in urine and whole blood associated with amalgam exposure in a US military population. J Dent Res 1998:77:461-71.

30 Woods JS, Martin MD, Leroux BG, et al. The contribution of dental amalgam to urinary mercury excretion in children. Environ Health Perspect 2007:115:1527-31.
31 Passos CJ, Mergler D, Lemire M, et al. Fish consumption and bioindicators of inorganic mercury exposure. Sci Total Environ 2007;373:68-76.

32 Berardi R, Pellei C, Valeri G, et al. Chromium exposure and germinal embryonal carcinoma: first two cases and review of the literature. J Toxicol Environ Health $A$ 2015;78:1-6.

33 Wilbur S, Abadin H, Fay M, et al. Toxicological Profile for Chromium. Atlanta, 2012.

34 Cavallari JM, Eisen EA, Fang SC, et al. PM2.5 metal exposures and nocturnal heart rate variability: a panel study of boilermaker construction workers. Environ Health 2008;7:36.

35 Williams M, Todd GD, Roney N, et al. Toxicological Profile for Manganese. Atlanta (GA) 2012

36 Jiang Y, Zheng W. Cardiovascular toxicities upon manganese exposure. Cardiovasc Toxicol 2005:5:345-54.

37 Barrington WW, Angle CR, Willcockson NK, et al. Autonomic function in manganese alloy workers. Environ Res 1998;78:50-8.

38 Jomova K, Valko M. Advances in metal-induced oxidative stress and human disease. Toxicology 2011;283:65-87.

39 Chuang HC, Hsueh TW, Chang CC, et al. Nickel-regulated heart rate variability: the roles of oxidative stress and inflammation. Toxicol Appl Pharmacol 2013;266:298-306.

40 Hajiasgharzadeh K, Mirnajafi-Zadeh J, Mani AR. Interleukin-6 impairs chronotropic responsiveness to cholinergic stimulation and decreases heart rate variability in mice. Eur J Pharmacol 2011;673:70-7.

41 Wiggers GA, Peçanha FM, Briones AM, et al. Low mercury concentrations cause oxidative stress and endothelial dysfunction in conductance and resistance arteries. Am J Physiol Heart Circ Physiol 2008;295:H1033-H1043.

42 Tormod N, Bjørn-Helge M. Understanding the collinearity problem in regression and discriminant analysis. Journal of Chemometrics 2001;15:413-26.

43 Papp A, Pecze L, Szabó A, et al. Effects on the central and peripheral nervous activity in rats elicited by acute administration of lead, mercury and manganese, and their combinations. J App/ Toxicol 2006;26:374-80.

44 Paustenbach DJ, Panko JM, Fredrick MM, et al. Urinary chromium as a biological marker of environmental exposure: what are the limitations? Regul Toxicol Pharmacol 1997;26:S23-S34.

45 Bader M, Dietz MC, Ihrig A, et al. Biomonitoring of manganese in blood, urine and axillary hair following low-dose exposure during the manufacture of dry cell batteries. Int Arch Occup Environ Health 1999:72:521-7. 